\title{
Demandas Populares Urbanas no Brasil: Formas Educativas da População
}

\section{Maria da Glória Gohn /}

Universidade Estadual de Campinas (Unicamp)

Objetiva sistematizar $c$ refletir sobre as principais demandas formuladas pelas camadas populares, em núcleos urbanos brasileiros, em especial na cidade de São Paulo, nas fases do Brasil Colônia, Império e primeiros anos da República. Interessa-nos, em geral, nas demandas relativas ao cotidiano daquelas camadas, as que dizem respeito à aquisição de bens e equipamentos coletivos para sobrevivência no diaa-dia. Em particular, interessa-nos as demandas relativas aos aparelhos e sistemas educacionais existentes na época. As fontes básicas dos dados deste trabalho são estudos, teses e livros, assim como a literatura e as atas de órgãos públicos oficiais da época (Atas das Câmaras Municipais).

\section{Introdução}

Este trabalho tem por objetivo refletir sôbre o processo de aprendizagem cultural gerado na relação povo-poder, no Brasil Colonial c Império, no que se refere a questões vivenciadas no cotidiano pela população tais como: vias c meios de transportes, uso de áreas comuns, uso do solo, abastecimento de água e gêneros de primeira necessidade, segurança etc.

Desde logo é importante registrar, em primeiro lugar, que trabalhamos com um conceito amplo de educação e, em segundo, que concebemos a educação de forma associada a outro conceito, o de cultura. Isto significa que a educação é abordada enquanto forma de ensino/ aprendizagem adquirida ao longo da vida dos cidadãos; pela leitura, interpretação c assimilação dos fatos, eventos e acontecimentos, que os 
indivíduos fazem, de forma isolada ou $\mathrm{cm}$ contato com grupos e organizações. A educação cscolar-formal-oficial, desenvolvida nas escolas, ministrada por entidades públicas ou privadas, é abordada enquanto uma das formas da educação (Gohn, 1992).

A cultura é concebida como modos, formas c processos de atuação dos homens na história. Ela se constrói na história, está constantemente se modificando mas, ao mesmo tempo, é continuamente influenciada por valores que se sedimentam em tradições, e que são transmitidos de geração a geração. A educação de um povo consiste no processo de absorção, reelaboração e transformação da cultura existente, gerando a cultura política de uma nação ${ }^{1}$.

Um dos pressupostos básicos deste trabalho é o de que vários elementos da cultura política brasileira do final do século XX foram gerados no período colonial. Estes elementos constituem, atualmente, obstáculos para a modernização das relações sociais no País. Dentre estes elementos destacamos o chamado "jeitinho" de levar vantagem, o clientelismo, a corrupção, a desconfiança nas instituições estatais, o machismo c a valorização dos bacharéis. Todos estes elementos são partes constitutivas da cultura política nacional, particularmente entre as camadas populares, e suas origens datam do período colonial.

A educação não formal ${ }^{2}$ sempre foi um campo de importância menor entre os estudiosos da educação brasileira, assim como nas políticas públicas do País. Todas as atenções sempre estiveram concentradas na educação formal, desenvolvida nos aparelhos escolares institucionalizados,

'A respeito da categoria politica, estamos trabalhando com as formulações de Bobbio (Dobbio, Materecci, Pasqueno, 1985).

'Estamos utilizando a expressão "educação nao formal" para designar processos envolvendo: aprendizagem politica dos direitos dos indivíduos enquanto cidadãos; a conscientização dos indivíduos através da participação cm atividades grupais, em relação à compreensão de seus interesses, do meio social e da natureza que o cerca; capacitação dos indivíduos para 0 trabalho, através da aprendizagem de habilidades e/ou desenvolvimento de potencialidades; a aprendizagem e o exercício de práticas que capacitam os indivíduos a se organizarem com objetivos comunitários, voltados para a solução de problemas coletivos cotidianos; a educação transmitida pelos pais na família etc. Os espaços onde se desenvolvem, ou se exercitam* as atividades da educação nao fonnal sito múltiplos, a saber: na casa-familia, no bairro-associaçao; nas igrejas, nos sindicatos c nos partidos politicos; nas organizações nao governamentais, nos clubes, teatros c outros espaços culturais etc. A aprendizagem da escrita e da leitura através de procedimentos c métodos nao oficiais é considerada por alguns autores como sendo parle da educação nao formal. Entretanto, preferimos caracterizar esta modalidade como educação informal, ou seja, os mesmos conteúdos da escola formal desenvolvidos em espaços alternativos e com metodologias di ferenciadas. 
ou nos processos informais de aprendizagem, desenvolvidos fora das unidades escolares, como as campanhas de alfabetização de adultos.

O paradigma teórico de nossa investigação parte do suposto que, usualmente, toda demanda gera, ou constitui-se, um processo educativo para a população reivindicante. O caráter educativo deste processo é dado pela aprendizagem obtida, quanto aos assuntos em tela; pelo papel dos agentes c atores envolvidos; e pelas estratégias ou resistências que são elaboradas.

Os anos 80 de nosso século trouxeram de volta os processos de mobilização e de organização da população e com eles a educação não formal voltou ao cenário nacional com grande relevância. Os temas dos direitos sociais c da cidadania estão no centro desta nova fase. Estes fatos foram as causas básicas que nos levaram à produção deste trabalho. Resgatar as origens, compreender as semelhanças $\mathrm{c}$ as diferenças, resgatar as próprias ações e práticas coletivas da população, foram nossas motivações iniciais.

Objetivando facilitar a análise, dividiremos a exposição dos acontecimentos por séculos (XVI ao XIX). A escolha deste critério é de ordem apenas temporal, pois nos interessa a recomposição dos cenários históricos. O regime político vigente - Colônia, Império e República é um determinante básico no interior da periodização adotada.

Nosso ponto de partida é a análise das tensões c dos conflitos gerados entre uma administração dominadora, interessada, inicialmente, apenas na extração de bens e na cobrança de impostos, e a população local, profundamente heterogênea, mas com um denominador comum: carências de todos os tipos. Iniciaremos abordando os conflitos gerados nos núcleos urbanos, procurando extrair das demandas e das ações populares o caráter educativo conferido a seus participantes e os conteúdos culturais que foram criados, destacando-se aqueles que posteriormente se sedimentaram como parte da cultura do País.

Cumpre registrar ainda, nesta introdução, que tomamos como referência, fundamentalmente, dados relativos à cidade de São Paulo. 
Utilizamos como fontes estudos realizados sôbre os períodos Colonial c Imperial, elaborados a partir de atas c documentos da época, $\mathrm{cm}$ especial as Atas da Câmara da Província de São Paulo.

\section{A relação povo-poder no século XVI: tensões e conflitos populares no Brasil Colonial}

Não pretendemos fazer uma reconstituição histórica exaustiva das lutas e dos processos reivindicatórios populares no período da Colônia, mas tão-somente registrar algumas dessas lutas, pois cias atestam a presença das camadas populares na cena política brasileira, pailicularmentc cm São Paulo, buscando extrair os processos educativos gerados.

Janicc Theodoro da Silva (1984), num estudo primoroso sôbre São Paulo, assinala:

No estabelecimento de formas de pagamento é que se inicia, para além da contradição básica Mctrópolc-Colônia, uma série de antagonismos internos à vida da Colônia... Os habitantes cia Vila de Piratininga, além de terem de fornecer o gado para a colonização de outras áreas, eram obrigados a conduzir este gado pela Serra do Mar e cm Santos oferecê-lo cm troca de qualquer mercadoria. O resultado foi o posicionamento radical (ou seja, não enviar gado) do "povo" na Câmara cm relação ao governador e ao provedor.

E prossegue a autora:

A população das vilas, além de pagar uma série de impostos à Coroa, era obrigada a edificar e conservar a povoação, baseando-se nos referenciais urbanos da Metrópole (Silva, 1984).

Observa-se que a construção do espaço urbano c, fundamentalmente, a manutenção dos equipamentos constituintes deste espaço, eram tarefas "do povo". Não havia um projeto estatal de organização do espaço; este se criava em função das necessidades da população. Da parte do Estado português havia uma única exigência: ocupar o território. 
A conservação das ruas, muros e construções de taipa cabia aos moradores, os quais estavam sujeitos a multas se não cumprissem tais obrigações. A multa era a forma de controle sôbre o urbano c sobre a população. Embora não possamos trabalhar com delimitações precisas sôbre o urbano c o rural, na primeira fase do Brasil Colonial (século XV), como bem assinala Janicc T. Silva, observamos que o controle fiscal exercido sobre "o povo" redundava numa dificuldade para a própria constituição do urbano. A este respeito Janicc Theodoro da Silva (1984, p.39) observa:

As exigências a que era submetida a população pela Coroa e, principalmente, a obrigação constante cie pagar Tintas à administração local, resultaram $\mathrm{cm}$ fugas constantes dos habitantes da cidade para o interior. Não para povoar, mas para escapar da "vassalagem" que tinham que prestar à ainda precária administração local.

Com muita propriedade a autora conclui: "É cm torno do fisco que se articula o urbano". E será contra o fisco que se registrará o primeiro movimento de resistência popular que temos notícia cm São Paulo. Tratase de movimentos produzidos por personagens que cometiam verdadeiros atos heróicos, pois, burlar o fisco conferia aos faltosos penas que iam de multas até o degredo, passando pelas prisões.

O pagamento dos tributos tinha reflexos também na divisão do trabalho existente. Os "homens bons", isto é, os colonos proprietários de terras doadas pela Coroa, empregavam mão-de-obra servil indígena para a realização dos serviços exigidos pela administração colonial. As tarefas não eram poucas. Além dos cuidados que se exigiam dentro dos muros, ainda restavam os campos, $\mathrm{cm}$ torno da vila, que precisavam ser limpos e cercados. Além das tarefas de conservação da cidade exigia-sc também tarefas de construção, contratadas pela Câmara, a cargo dos artesãos imigrantes. Esta categoria social se realiza $\mathrm{cm}$ funções eminentemente urbanas. "As obrigações e direitos dos artesãos eram especificados através de posturas e taxas" (Silva, 1984, p.45). 
A desobediência a estas posturas parece ter sido uma constante. $\mathrm{O}$ resultado desta situação foi o surgimento de inúmeros conflitos entre os artesãos, pertencentes ao "povo", e a administração local.

Cumpre assinalar, ainda, as tensões e os conflitos havidos entre colonos e jesuítas, no início da colonização paulista. O trabalho de catequese dos jesuítas, nas aldeias, criava nos colonos uma disponibilidade de mão-de-obra dócil, ordeira e laboriosa. São inúmeros os registros históricos que possuímos acerca do projeto colonizador dos jesuítas e a missão de converter os pagãos aos "bons costumes da civilização". Porém, os colonos, para contarem com tal mão-de-obra, estabeleciam regras duras. Os grupos de índios eram aprisionados e condenados a trabalhar sem ter em contrapartida o apoio moral e simbólico, dado pela religião. As fugas eram constantes. Os atritos entre os colonos e os jesuítas estavam acirrados quando os últimos foram expulsos do Brasil.

\section{Educação e cultura brasileira no século XVI}

Do relato das páginas anteriores observa-se que, desde o início da colonização brasileira, a população foi obrigada a engendrar estratégias de resistências às formas de dominação a que era submetida. O controle exercido sobre a população através do fisco e as normas e posturas a serem cumpridas para sobreviver nos núcleos urbanos levavam a fugas, desobediência civil e conflitos.

A educação dada pelos jesuítas não contribuía para a construção de uma cultura libertadora. Não havia instrução pública. Conforme atesta José Ricardo Pires de Almeida (1989, p.29):

Até então (1710) as escolas de todos os tipos estavam sob a direção dos jesuítas ou de seus discípulos, com intervenção maior ou menor das municipalidades; o governo central nada regulamentava. Incumbia-se especialmente de assegurar a posse e o domínio de todo o país, compreendido entre a Amazônia e o Prata, até as vertentes dos Andes.

O "povo" tinha que construir suas próprias condições de sobrevivência no meio urbano (abrir ruas, conservá-las, construir muros, 
valas, passagens, pontes sobre córregos etc) e pagar altos impostos ao fisco. Não havia nenhuma contrapartida. O resultado disto foi a aprendizagem da necessidade de resistir, não pagando taxas, burlando a lei, quando não se entrava em conflito direto. Não havia direitos ou Poder da Justiça para socorrer. Daí a desconfiança c a busca de estratégias de "dar-se um jeito".

\section{A relação povo-poder no século XVII}

O século XVII assinala uma inversão de funções dos agentes que participam da construção do urbano no Brasil. Em São Paulo, o desenvolvimento econômico da vila, dado pela sua transformação em entreposto comercial de Santos (para onde envia gado c farinha), pela intensificação do aprisionamento c tráfico indígena e, posteriormente, pelos eventuais bandeirantes $\mathrm{cm}$ busca de pedras $\mathrm{c}$ minas, todo este contexto levou a uma reformulação das atividades administrativas da Coroa e, conseqüentemente, do poder público.

As tarefas relativas aos bens $\mathbf{c}$ aos espaços de uso comum deixam de ser obrigação dos colonos c passam a ser dever do Estado. Constituise assim uma nova categoria espacial, a do uso para bem comum. Estes espaços transcendiam os limites da vila c, fundamentalmente, abrangiam os caminhos que levavam ao comércio e às fontes de bens e riquezas.

A Câmara passará a administrar o movimento de seus habitantes e a conservação das estradas, elementos vitais para a sobrevivência do núcleo colonizador. (Silva, 1984, p.53)

E em torno do fisco que também ocorrerão as principais tensões e movimentos populares no século XVI no Brasil.

Com acentuada frequiência, a Câmara dispõe sôbre o comercio da farinha, do gado, do couro e dos panos. Tanto a conta legal (pagamento dos dízimos) como a ilegal (sair da vila para revender produtos fora da capitania sem 
ordem da Câmara) geravam dividendos à máquina estalai. Num período de fome dentro da cidade, por exemplo, o povo delatava a saida de farinha ou de carne, dividindo a multa cobrada ao infrator entre acusador e Câmara. Portanto, a própria fome regulava nessa conjuntura a intensidade da fiscalização, através desse expediente político, utilizado pelo listado colonizador. (Silva, 1984, p.58)

O extenso relato acima nos demonstra, cabalmente, uma forma de ação popular no qual o institucional é utilizado como mecanismo de defesa c resistência. Um mecanismo de controle c apropriado pelo "povo" no sentido de, através da cobrança de sua efetivação, tirar vantagens que lhe possibilitem espaços de sobrevivência.

As categorias da ordem legal c da ordem ilegal são acionadas segundo a dinâmica das relações existentes pelos dois lados: dominantes c dominados. É nesse contexto que a categoria do "bem comum" assume significado. E a dialética torna-se contraditória. O institucional criado como mecanismo de controle transfigura-se $\mathrm{cm}$ mediador, regulador $\mathrm{c}$ organizador das relações sociais sob o rótulo de bem comum. É essa mesma dialética que abre espaço para que "o povo" encontre formas paralelas para sobreviver, criando mecanismos de sobrevivência às duras condições a que estava submetido.

São as instituições criadas pela Metrópole que os "salvam" (o povo) da fome c que organizam as relações existentes entre os diversos setores da sociedade. O surgimento do bem comum legitimará a presença do Estado como organização do sistema de dominação, encarnado pelo poder da então Câmara Municipal.

Progressivamente, o direito de alguns passou a ser eleito como a vontade em nome de todos. Estas estruturas se consolidaram à medida que as noções de propriedade privada e propriedade comum (praças, caminhos) emergiram. Os chamados homens bons se apossaram de determinadas áreas, através do poder das Câmaras, declarando-as "bem comum". A medida que passa a ocorrer uma expansão do sistema colonial, e a acumulação começa a se fazer às custas do rompimento das barreiras c obstáculos geográficos (ciclo das minas), as áreas do bem 
comum passam a ser vitais para possibilitar a circulação dos homens e das mercadorias apreendidas.

Os conflitos $\mathrm{cm}$ torno do uso do solo, entre os moradores c o Estado datam, assim, desde os primórdios do período colonial. Os colonos fugiam das áreas demarcadas pela Coroa para escapar do ilsco c ocupavam áreas de território indígena. A Câmara procurava, num segundo momento, incorporar as áreas ocupadas à sua jurisdição, fazendo novas demarcações. O espaço urbano começa a tomar corpo, enquanto área demarcada. A fuga dos moradores, por motivos de tradição, leva à expansão da vila. Os bairros, células fundamentais de configuração da cidade moderna, surgem através destes mecanismos de confronto entre moradores c Estado. Os Capitães de Bairros, espécie de Companhia de Homens para manter a ordem nas estradas da vila, eram auxiliares civis das Câmaras c gênese embrionária das lideranças das Associações de Moradores contemporâneas ${ }^{3}$.

\section{Educação e cultura brasileira no século XVII}

No século XVII, observamos alterações significativas na relação povo-poder com a tomada de responsabilidade de algumas tarefas pelo poder público. $\mathrm{O}$ argumento da categoria do uso comum demarca o estabelecimento de relações sociais existentes desde o modo de produção antigo, cm Roma ${ }^{4}$. Novamente as relações comerciais foram as responsáveis pelas transformações, estendendo os limites das vilas e criando tensões c conflitos $\mathrm{cm}$ torno das cobranças. Em épocas de crise e fome na cidade, populares c oficiais da administração estabeleciam práticas ilegais, corruptas.

Também nessa época a idéia de bem comum veio a estabelecer um parâmetro para a ação estatal, colocando-o como agente acima das classes e camadas, c legitimando suas ações. Não se trata ainda da noção plena

-Ver pesquisas anteriores que realizamos sôbre a história das Sociedades Amigos de Bairros em Sào Paulo em Gohn, 1982.

${ }^{4}$ Ver analise de Hobsbawnn, 1972. 
de espaço público pois, o espaço comum decorria mais da fragilidade das estruturas da época, da necessidade de enfrentar problemas cotidianos, como o de transporte até as minas ou até os portos. As. áreas de bem comum foram se tornando também formas de apropriação c de dominação, gerando aprendizado para gananciosos, que delas se apoderavam através do suborno ou do poder nas Câmaras, assim como, aprendizado de resistência para a população, à medida que esta saía das áreas demandadas pela Coroa, para fugir de seus encargos, gerando outro problema social que era a invasão das áreas indígenas.

As áreas de bem comum foram um "artefato humano", para usarmos expressões de Arendt (1981); elas foram os embriões dos espaços públicos no Brasil, deram visibilidade a seus ocupantes e às funções que nelas eram desempenhadas.

\section{A relação povo-poder no século $\mathbf{X V I I I}$}

O século XVIII significa para São Paulo a aquisição de uma identidade própria, enquanto cidade com uma série de equipamentos distintos dos da zona rural c seus povoados. Esgotos, pontes, calçadas e pedras nas ruas passam a ser os elementos materiais básicos dessa identidade. A divisão espacial entre arrebalde, bairros e freguesias também se consolida.

A cidade estrutura também seus mecanismos de controle. $\mathrm{O}$ aparelho repressor foi um dos primeiros a ser acionado sendo a forca seu símbolo máximo. O controle fiscal continua sendo a maior fonte de receitas do erário público. A cobrança de multas por estabelecimentos irregulares (açougues, principalmente) passa a ser uma nova forma de conflito entre a Câmara e a população.

A área de bem comum - representada principalmente pelas pontes - continuou a ser de responsabilidade da Câmara. Os vereadores, além de sua função no governança da vila, controlavam a fiscalização da cobrança de impostos para a Coroa portuguesa. Controlavam, ainda, de 
maneira pouco sistemática, as vendas que se desenvolviam no interior da vila. Obrigavam também a população, através de um código de posturas, a limpar a cidade dos formigueiros e dos matos. E, ainda, determinavam a feitura ou o conserto de alguma ponte, cuja localização fosse importante para o Caminho do Mar — via de contato com o Exterior.

Entretanto, um elemento de grande importância ocorrido em São Paulo no século XVIII, que contribuiu decisivamente para sua unidade, foi a incorporação dos bairros à jurisdição da Câmara, expandindo o núcleo original. As pontes, elementos de ligação de toda cidade, passaram a ser consertadas pelos moradores dos bairros. Os bairros paulistanos significativos dessa época eram Santo Amaro e Penha.As atuais cidades de Atibaia e Juqueri também eram regiões sob jurisdição da Câmara paulistana, assim como Cotia.

A configuração da vila numa cidade com um núcleo central e bairros acarretou, também, o surgimento de inúmeros novos conflitos urbanos. Nos dois séculos anteriores não houve uma preocupação, por parte dos órgãos oficiais, com o planejamento urbanístico da cidade. As ruas não tinham a menor importância, pois o que contava eram as casas c seus respectivos muros protetores. Com o desenvolvimento comercial do século XVIII, as ruas passam a ser elementos definidores do espaço urbano c geradores de conflitos.

As cxigências institucionais eram inúmeras o que levava a população a alegar a impossibilidade de atendê-las. As medidas de embelezamento da vila - como fazer calçada, por exemplo - eram vistas como inoportunas. (Silva, 1984, p. 112)

Na segunda metade do século já surgem preocupações com as chamadas benfeitorias públicas. Chafarizes e bicas passam a ser elementos da cidade, a princípio construídos pelos padres do Convento de São Francisco e mantidos pela Câmara.

Finalmente, a estruturação urbana de São Paulo no século XVIII leva o Estado a assumir — sempre através da Câmara — o papel 
organizador geral do espaço urbano, definindo não só formas de ocupação do solo mas também seus modos. Os interesses públicos impõe-se aos privados.

A medida que se monta a dualidade entre público e privado, o Estado elimina a possibilidade de ser visto como instrumento de dominação de classe. Criase uma serie de lugares públicos (largos, praças, chafarizes, ruas etc.), onde os colonos irão exercitar-sc para se tornarem homens civilizados "policiados" como se dizia no século XV111 — , capazes de viver na urbe. (Silva, 1984, p. 121)

\section{Educação c cultura brasileira no século XVIII}

Várias alterações podem ser observadas no século XVIII no Brasil, em relação à educação e à cultura. A expulsão dos jesuítas c a secularização do ensino feita pelo Marquês de Pombal levaram a reformulações na educação formal, no nivel secundário, com alterações no latim, grego, hebraico $\mathbf{c}$ arte da retórica. O ensino primário continuou quase inexistente. Fora do âmbito da educação formal, da instrução propriamente dita, vemos o surgimento de uma categoria de cidadãos, dada pelos usufruidores de bens coletivos da cidade: os moradores consumidores de águas dos chafarizes $\mathrm{c}$ bicas. Estes mesmos cidadãos resistem às primeiras medidas que objetivavam o embelezamento das cidades, por implicarem mais ônus econômico c mais trabalho comunal. O público ganha o status de espaço, de lugar gcográfico-cspacial, através das praças c ruas.

O controle da população pelo fisco, $\mathbf{c}$ a punição, que poderia ser até a morte na forca, continuaram a ser os mecanismos básicos de mediação das relações povo-poder, ou seja, não encontramos, até o século XVIII, formas civilizadas, democráticas c cidadãs, no regimento das relações povo-governo. Consequientemente, a cultura política que foi sendo gerada era de desconfiança e/ou medo do poder público, de descrédito de sua função de justiça. Engendrar estratégias de sobrevivência era a 
preocupação generalizada. Não havia identidade da coisa pública como coisa dos cidadãos. O público era identificado com o poder público-cstatal, e este último era visto como uma ameaça à vida do então não-cidadão.

\section{A relação povo-poder no século XIX}

No início do século XIX, São PAULO passou a ser uma cidade com ruas nomeadas e casas numeradas. A antiga Vila, transformada paulatinamente $\mathrm{cm}$ centro comercial, ganha $\mathrm{cm} 1850$ um projeto de postura que caracteriza os novos padrões de uso c ocupação do solo. Normas quanto à divisão das funções espaciais e à padronização de fachadas são regulamentadas. A estratificação sócio-espacial se intensifica com a especificação imobiliária dos terrenos. Os aluguéis atingem somas exorbitantes e passam a ser um problema urbano.

A política de ocupação do solo paulistano no século XIX levou a uma diferenciação das áreas comerciais c residenciais, negando os padrões anteriores, que não distinguiam bem as áreas urbanas das rurais (chácaras). Passa a ocorrer um processo de inversão á política das áreas do bem comum. As áreas públicas passam a ser privatizadas c as chamadas zonas ou trechos de servidão pública passam a ser motivo de constantes litígios, principalmente entre os proprietários vizinhos ás mesmas.

O questionamento sobre a propriedade c uso do solo passa a ser tema freqüentemente diseutido ao nivel institucional, com a Câmara procurando, cada vez mais, atuar no sentido de satisfazer às exigências dos proprietários, sem, contudo, prejudicar o comércio, atividade econômica extremamente importante para a cidade. (Silva, 1984, p. 142)

É, entretanto, a partir do século XIX que podemos falar de uma verdadeira política de urbanização em São Paulo, por parte do Estado. Este deixa de ser mero agente fiscalizador e cobrador, passando a assumir as funções de ordenador do espaço urbano. O controle da propriedade será tema central. 
Os problemas urbanos da época como trânsito, banditismo etc, configuram-se neste século como problemas sociais. Eles eram de outra ordem; envolviam formas c modos diferenciados. Os acidentes de trânsito envolviam animais e os matagais de várias ruas eram esconderijos de "bandidos".

A Câmara será dotada de um esquema racional de administração na qual as antigas funções de fiscalização serão promovidas a gabaritos técnicos, entregues a peritos (engenheiros) responsáveis pela estrutura racional da nova cidade. A objetividade $\mathrm{c}$ a neutralidade entram $\mathrm{cm}$ cena camuflando os critérios desiguais existentes na solução dos diversos problemas da cidade. O hábito de nomear comissões para melhor desempenho das tarefas passa a ser uma constante.

Com o crescimento do número de habitantes no início do século, a questão do abastecimento de água tornou-se crucial. Competia à Câmara resolver o problema e esta não agia como resultante de um conjunto de forças atuantes democraticamente. Ela atuava como um poder superior, que deveria ser acatado. Isto levou a uma série de conflitos entre o poder público c a população na solução do abastecimento de água, pois a desapropriação judiciária passou a ser um expediente constante em terrenos e propriedades particulares para a construção de chafarizes.

O problema da água, assim como outros problemas urbanos (luz e transportes, por exemplo), serão equacionados em termos do estabelecimento de novos critérios de urbanização da cidade nos quais são contratadas companhias particulares, com concessão do Estado, para explorarem os serviços coletivos urbanos. Os interesses privados passam a financiar a nova infra-estrutura urbana, baseados na lógica do capital.

\section{Educação e cultura popular brasileira no século XIX}

O século XIX no Brasil foi particularmente fértil no campo da educação e da cultura, quando comparado aos anteriores. Na educação, 
tanto formal como informal e não formal, inúmeros eventos ocorreram. $\mathrm{Na}$ área formal, graças à vinda da família real para o Brasil no início do século, quando o País era ainda Colônia, os historiadores são unânimes em atestar as inúmeras realizações ocorridas no campo da educação, da cultura e da arte. Na educação formal, embora a oferta da instrução primária para o povo tenha sido quase inexistente, constata-se a estruturação de uma proposta de educação para a nação brasileira, através de leis e obras 5 .

Entretanto, a questão econômica, tratada pelo ângulo da dominação/ espoliação, também se sobressai na área da educação formal, no período colonial brasileiro. Os professores eram mal remunerados e quase inexistentes. Ao contrário do senso comum vigente, a educação escolar já era uma área desprestigiada. A profissão era exercida na grande maioria por amadores e práticos, que pagavam taxas para obterem licenças para trabalhar.

Mas o destaque maior, durante o século XIX, no plano da educação, foi dado na área não formal. A série de lutas c movimentos empreendidos pela população atestam nossas afirmações. As mudanças na estrutura política e econômica do País foram responsáveis pela eclosão das novas políticas. A emancipação da condição de Colônia gerou inúmeros movimentos emancipatórios e a expansão de novas modalidades de exploração econômica, como a cultura do café. Esta última levou à urbanização da região sudeste e à geração de excedentes econômicos que propiciaram as bases para uma industrialização rudimentar. Uma nova categoria social entra no cenário dos conflitos no País. Trata-se dos imigrantes europeus que vieram inicialmente para as fazendas de café e que, progressivamente, vão se integrando também aos núcleos urbanos e à incipiente industrialização (o café exige o desenvolvimento de cidades,

*Data da época de D. João VI o primeiro projeto de educação brasileira pensado cm lermos de uma unidade, de autoria do Gal. F. Boya G. Stockler. Em 1827, teve-se a promulgação da primeira lei relativa a instrução pública. De 1821 em diante, disseminouse o méuxlo do ensino mútuo, sistema voltado para o ensino primário no qual há dois ou três professores instrutores c inúmeros monitores escolhidos entre os próprios alunos. Em 1929, criou-se uma comissão encarregaria de regul;imcntaras escolas primarias. 
para cuidar de sua comercialização e exportação, gerando conseqüentemente um mercado de trabalho urbano).

Francisco Foot e Victor Leonardi, ao analisarem a formação de indústrias no Brasil, assinalam que o século XIX foi extremamente rico quanto à cronologia de movimentos sociais. Assim se expressam:

Além dos já conhecidos e inumeráveis levantes de negros e das revoltas populares mais intensas (Balaiada, no Maranhão; Cabanagem, no Pará, com a formação de um governo popular revolucionário; a Revolução Farroupilha, no Rio Grande do Sul), pode-se citar uma série de motins das massas urbanas em torno de reivindicações populares imediatas, como a luta contra a escassez de gêneros de primeira necessidade e a carestia (...) No caso dos motins e explosões liderados por membros da população livre urbaria, eles coincidem com períodos de crises epidêmicas e de abastecimento de víveres, como, por exemplo, em Salvador, a revolta de 1858, após as sucessivas epidemias de febre amarela e cholera morbus e a escassez de gêneros em função das intempéries climáticas (Foot, Leonardi, 1982, p. 137).

Cumpre registrar, ainda, a série de movimentos de trabalhadores imigrantes, por melhores condições de trabalho e de moradia, no campo e na cidade, tão bem estudadas por José de Souza Martins (1986), que vieram a gerar, nas duas últimas décadas do século passado e nas duas primeiras do século XX, o vigoroso movimento anarco-sindicalista brasileiro, de ideologia social-libertária.

A articulação entre as demandas relativas ao mundo da produção e as relativas à reprodução dos trabalhadores e de sua família era uma constante nas inúmeras reivindicações operárias. Em 1891, por exemplo, uma petição encaminhada ao Congresso Nacional, por vários representantes das coletividades operárias e proletárias da Capital Federal, solicitava:

1. Decretação de um abatimento de $50 \%$ nos gêneros de primeira necessidade;

2. aumento de todos os impostos sobre bens supérfluos, de fantasia e de luxo; 
3. nacionalização do comércio;

4. controle e diminuição da taxa dos aluguéis de habitação.

É interessante assinalar que estas reivindicações têm sido interpretadas por certos cientistas sociais como reformistas, fruto dos limites de sua consciência de classe e de sua organização material. Tratase de uma interpretação equivocada sobre nossa história social, pois aquelas lideranças expressavam, através de suas demandas, um repúdio à situação concreta de vivência dos trabalhadores; manifestavam fundamentalmente uma visão de conjunto do cotidiano das camadas populares, por não desvincularem as reivindicações fabris das urbanas. Não se detinham no aspecto corporativista salarial, concentrando as reivindicações sobre a necessidade de controle e rebaixamento dos preços inacessíveis às camadas populares. Não se partia da categoria para atingir a sociedade mas da sociedade para a categoria.

O pauperismo urbano é observado, na época, através da existência de uma massa humana sobrevivendo em condições subumanas; faz parte da trajetória do capitalismo brasileiro, não sendo, portanto, fruto de seu desenvolvimento desequilibrado ou de seu estágio tardio. O periodo, do final do século passado ao início deste, assinala a existência de uma massa de despossuídos que perambulavam pelas ruas, a chamada turba urbana, condensação de desempregados ambulantes, prostitutas, artistas de rua, mendigos etc.

\section{Conclusões}

Ao realizarmos um détour na história brasileira ao longo de três séculos, durante seus períodos Colonial, Imperial, e primeiros anos da República, observamos que as condições coletivas desobrevivência no meio urbano foram construídas, no início, pela população, sob o controle de regras estabelecidas pela Coroa Portuguesa, e fiscalizadas pelas Câmaras 
locais. Existiam obrigações e encargos pesados e rígidos. O fisco era o principal agente mediador da relação povo-governo.

Com o desenvolvimento da Colônia $\mathrm{c}$ as alterações na política portuguesa, em geral, e em especial para com o Brasil, foram-se construindo as noções de bem comum c de poder público. Desde cedo estas noções não estiveram carregadas de características universalizantes, voltadas para o bem estar da maioria, mas se assentavam $\mathrm{cm}$ pressupostos para garantir interesses econômicos (da Colônia ou de proprietários individuais). Disto resultou que as noções do público c do bem comum geraram o seu contrário: a burla, a camuflagem, a corrupção c o clientelismo.

A relação povo-governo-administração foi permeada, ao longo dos séculos, de conflitos c contraditoriedades. O processo de aprendizado gerado junto à população, na leitura realizada no cotidiano, transfigurada com práticas e representações do senso comum, foi o de grande desconfiança em relação a tudo o que provem do setor público mas, simultaneamente, de busca de brechas c oportunidades para se aproveitar deste setor, pois o mesmo propicia a seus integrantes vantagens, benefícios e oportunidades.

Este trabalho tomou como base dados e fatos relativos às condições gerais, coletivas, para a sobrevivência no meio urbano. Poderíamos ter adotado outro partido, outros tipos de dados. O importante a demonstrar é que: a participação da população é um fato real que não pode ser relegado. Não é possível contar a história apenas pelo lado dos governantes e reis, como nos tem ensinado a Escola dos Annales desde 1929 (Burke, 1992). A participação popular, pelo lado da dominação ou da resistência, gera aprendizados, traduzíveis em duas dimensões a do próprio povo e a dos governantes, que reelaboram seus discursos e políticas. A cultura política gerada neste processo se traduz em valores que estão na população, e que condicionam e explicam suas práticas comportamentais e simbólicas. Trata-se de uma cultura política impregnada por valores tradicionais, típicos de uma civilização não moderna, pouco urbanizada, não 
industrializada. As características desta cultura foram gestadas no processo, na forma como ocorreu a relação povo-governo, e não tem nada a ver com a origem de um de seus membros partícipes, a Coroa Portuguesa, no caso.

Essa cultura política constitui, ao final do século XX, elemento fundamental que norteia o comportamento da população, enquanto atores demandatários, e do governo, enquanto agente distribuidor e regulador de bens coletivos. Essa cultura está totalmente despreparada para conviver com a era das comunicações e a linguagem da mídia ao final do século $\mathrm{XX}$, com a velocidade do desenvolvimento tecnológico, com o avanço das técnicas e da ciência $\mathrm{cm}$ geral. Disto resulta uma sociedade atomizada, atordoada, fragmentada c medrosa, que reage apelando para a violência, respondendo pelo lado irracional às agressões a que é submetida cotidianamente.

Referências bibliográficas

ALMEIDA, José Ricardo Pires. História da instrução pública no Brasil: 15001SS9. São Paulo: EUDC .-INEP, 1989.

ARENDT, Hannah."// condição humana. Rio de Janeiro: Forense, 1981.

ATAS da Câmara de São Paulo. Publicação da Divisão do Arquivo Histórico do Departamento de Cultura da Prefeitura de São Paulo.

AZEVEDO, Fernando. A cultura brasileira. São Paulo: Ed. Nacional, 1944.

BOBBIO, N., MATTERECCI, N., PASQUENO, G. Dicionário de política. Brasília: Ed. Universidade de Brasília, 1985.

BURKE, Peter. A Escola dos Annales. São Paulo: Ed. UNESP, 1992.

DEAN, Warren. A industrialização de São Paulo. São Paulo: DIFEL, 1972.

FAUSTO, Boris. Historiografia da imigração para São Paulo. São Paulo: Editora Sumaré, 1991. 
FOOT, Francisco, LEONARDI, Victor. História da indústria e do trabalho no Brasil. São Paulo: Globaj, 1982.

GOHN, Maria da Glória. Reivindicações populares urbanas. São Paulo: Cortez, 1982.

. Aforça da periferia. Petrópolis: Vozes, 1985.

. Movimentos sociais e lutas pela moradia. São Paulo: Loyola, 1991.

. Movimentos sociais e educação. São Paulo: Cortez, 1992.

HOBSBAWNN, Eric. Formações econômicas pré-capitalistas. Rio de Janeiro: Paz e Terra, 1972.

MARTINS, José de S. O cativeiro da terra. São Paulo: Hucitec, 1986.

PINHEIRO, Paulo S., HALL, M.M. A classe operária no Brasil. São Paulo: Alfa Omega, 1979.

PRADO, Antonio A. (Org.)Libertários no Brasil. São Paulo: Brasiliense, 1986.

PRADO, Caio P. História econômica do Brasil. São Paulo: Brasiliense, 1969.

RIBEIRO, M. Luisa S. História da educação brasileira. São Paulo: Cortez, 1987.

ROMANELLI, O. de O. História da educação no Brasil. Petrópolis: Vozes, 1988.

SCHWARZ, Roberto. Os pobres na literatura brasileira. São Paulo: Brasiliense, 1983.

SILVA, Janice Theodoro. São Paulo: 1554-1880 - o discurso ideológico e a organização espacial. São Paulo: Moderna, 1984.

Recebido em 7 de abril de 1994

Maria da Glória Gohn, doutora em Ciência Política e livre-docente em História da Arquitetura e do Planejamento, pela Universidade de São 
Paulo (USP), é professora adjunta da Faculdade de Educação da Universidade Estadual de Campinas (Unicamp).

The aim of this paper is to discuss the main popular demands in urban centres during the Colonial and Imperial periods of Brazil histoiy, and the initial decades of the Republic in the XX century. We are interested in the everyday demands that refer to the public equipment used for survival in that time. The basic source of information in this paper are: researches, studies, tesys and books, and also the literature and public documents from the analized period.

Ce travail a pour objectif sistématiser et reflechir sur les principales revindications formulées par les couches populaires dans les centres urbains pendant le Brésil-Colonie, l'Empire et les premières années de là Republique. Ce que nous interesse, en general, ce sont les demandes concernant le quotidien de ces couches, celles qui ont à I'acquisition de biens et d'equipements collectifs pour là survie aujour. $D$ 'un point de vue particulier, ce qui nous interesse ce sont les demandes qui se rapportent aux appareils et aux systèmes éducationnels existants à cette époque-là. Les principales sources des donnés de ce travail sont des études, des thèses et des livres ainsi que là littérature et les Actes des Chambres Municipales recouvrant les périodes mentionnées ci-dessus.

El trabajo tiene por objetivo sistematizar y reflexionar sobre Ias principales demandas formuladas por Ias clases populares de los núcleos urbanos, en Ia época del Brasil Colônia, Império y primeiros anos de là República. Nos interesan, en general, Ias demandas relativas al cotidiano de aquellas clases, principalmente, las que se refieren a là adquisición 
de bienes y equipamientos colectivos para su sobrevivência diária. En particular, nos interesan, Ias demandas relativas a los aparatosy sistemas educacionales en là época. Las fuentes básicas de datos de este trabajo son: estúdios, tesis y libros, así como también literatura y actas de organismos públicos oficiales de Ia época. 